\begin{tabular}{c} 
journal homepage: http://ijiemjournal. uns.ac.rs/ \\
International Journal of Industrial \\
Engineering and Management \\
Volume $12 /$ No $4 /$ December $2021 / 228-242$ \\
\hline
\end{tabular}

Review article

\title{
Research Trends and Topics in IJIEM from 2010 to 2020: A Statistical History
}

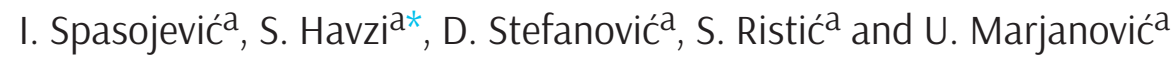 \\ a University of Novi Sad, Faculty of Technical Sciences, Department of Industrial Engineering and Management, Novi Sad, Serbia;
}

\section{A B STRACT}

Purpose of this paper is to determine changes in the research trends in the International Journal of Industrial Engineering and Management by analyzing trends and topics covered by its papers that were published from 2010 to 2020 and available in the Scopus database. Keywords and titles of papers were identified. Analysis was conducted both summarized for all eleven years and individually for intervals of three years. Results showed that the most popular topic was mass customization. Also, usage of information technologies in managerial and engineering processes is becoming immensely popular in the last few years.

\section{ARTICLE INFO}

Article history:

Received June 16, 2021

Revised November 11, 2021

Accepted November 15, 2021

Published online November 17, 2021

Keywords:

bibliometric analysis;

Scopus;

industrial engineering;

engineering management;

${ }^{*}$ Corresponding author:

Sara Havzi

havzisara@uns.ac.rs

\section{Introduction}

The concept of manufacturing has changed significantly throughout history, especially during four industrial revolutions [1], [2]. The transition from individual to mass production has led to the need for companies to adapt to changes to survive in the market. Increased export and the processes of globalization have led to a complete transformation of the businesses. It often happens that companies shift their business focus from manufacturing to a service-based company [2]. In addition to this, the increased use of information technology in production and business processes, as well as process automation, are leading businesses to the need for adaptation to new market demands [3]. Considering these facts, we are witnessing the situation where companies are constantly implementing new technologies, tools, and methodologies to their business policies [4][5]. These changing needs bring along demands to research different trends and topics that were popular in companies within a certain period, especially from the industrial engineering and management science aspects.

Given that the International Journal of Industrial Engineering and Management (IJIEM) has been publishing papers for more than a decade, conducting a retrospect of the main trends and research topics covered by this community in the last 11 years, from 2010 to 2020 , could be important in predicting the future course of business trends in this field. The 
IJIEM is an interdisciplinary international academic journal published quarterly. It serves researchers in the industrial engineering, manufacturing engineering, and management fields. Its major aims are to collect quality information about current trends in the field of industrial engineering and management, to recommend new methodologies in this field as well as new ways for their application in the industry [6].

This paper is aimed to analyze the research topics covered by the IJIEM, from its establishment in 2010 to the present. The main motivation for this research can be found in the assumption that developing a retrospective of the IJIEM, by its main topics of interest, can significantly contribute to the process of determining the general relevance, impact, and progress of the industrial engineering, manufacturing engineering, and management communities since 2010. Additionally, this review paper will provide information about future research opportunities for authors of IJIEM papers. In this way, authors may be able to forecast which topics should be prioritized in the near future, as well as which scientific areas have the potential to yield new, major scientific discoveries. To attain this goal, we gathered all the IJIEM papers that could be found in the Scopus [7] database for the previously mentioned period of time. Specifically, keywords and titles of every paper were identified with a purpose to determine which topics were most studied. Analysis was conducted both summarized for all eleven years and individually for intervals of three years.

The remainder of this paper is organized as follows: In Section 2, a methodology that was used alongside the planning and conducting the review phase is shown. Obtained results are presented in Section 3. Special attention is paid to the distribution of research topics throughout the years. In Section 4, research results are discussed and analyzed. Finally, the conclusion is given in Section 5.

\section{Methodology}

Bibliometric analysis (please see: [8], and [9]) in the field of industrial engineering and engineering management, commonly relies on structured data (i.e. keywords, titles). Those data are provided by global database, such as Web of Science [10] and Scopus [11]. To discover trends and topics covered by a journal, the current paper uses traditional bibliometric analysis to identify the topics that have received the most attention in the history of the IJIEM.
We have adopted a novel methodology approach proposed by the Romero-Silva and Marsillac [12]. First, we identified the source of articles with the structured data, then we retrieved the data, processed the data, and analyzed the data (Figure 1).

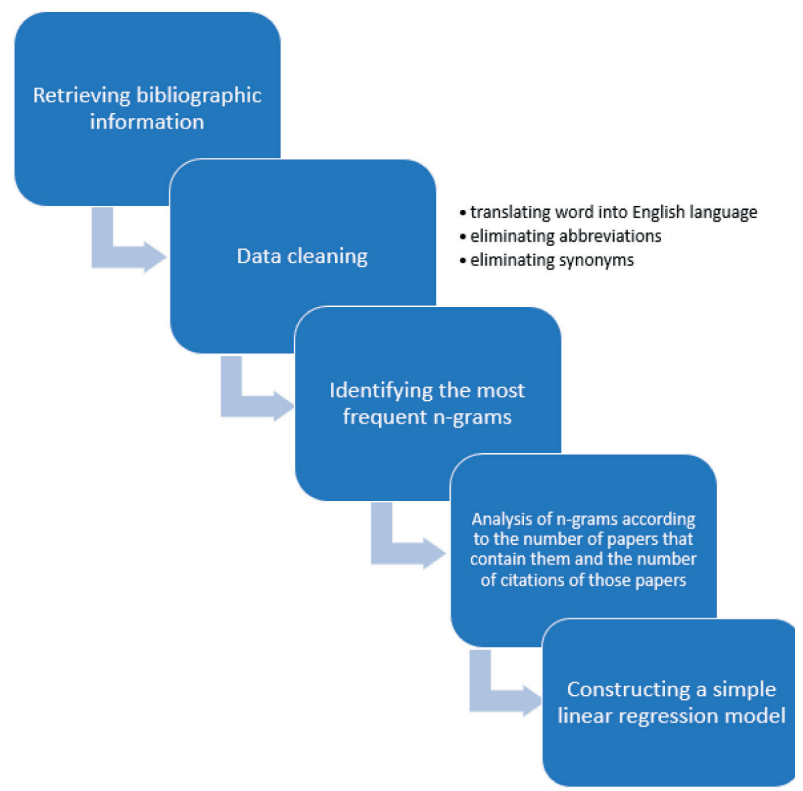

Figure 1. Methodology steps used in this paper

The first step to start the bibliometric analysis was to retrieve bibliographic information on the papers that were published in the IJIEM. To fulfill this purpose the Scopus [11] database was used. Only the IJIEM papers whose data are available in the Scopus database are included in the analysis. The first paper in this journal was published in March 2010 while the last paper covered by this research was published in December 2020. Information that was retrieved from all 245 papers consisted of features such as Authors, Keywords, Title, Publication Year, Abstract, Number of Citations, and Authors Affiliations. Data were collected in February 2021.

At the beginning of the research, it was necessary to clean the data to create a relevant basis for further analysis. The cleaning phase was done manually using Microsoft Excel. Firstly, all words that were not written in the English language were translated into it. After that, synonyms that were written in British and American English were brought down to one common term - written in American English. The next challenge that needed to be solved was to eliminate abbreviations of some words. Such text was merged with its full name and deleted from the list of independent terms for analysis. Besides that, many terms were written both in the plural and singular forms. In the cleaning phase, these terms were merged in their singular form. There was also a situation where 
two or more terms that are synonyms appeared in the same paper as different keywords (for example - lean manufacturing and lean production). These synonyms were in the analysis considered as one term in one paper and were, later, counted only once with a purpose to make the research as accurate as possible. Lastly, terms that often occurred in a combination with keywords or titles but were not significant for this research have been omitted (e.g., about, new, developing, proposed).

After the text was cleaned, it was ready for analysis. The first step of the analysis was to identify the most frequent terms of $n$ words (n-grams) that occurred in papers. N-grams were grouped in three sets - terms consisting of one word $(n=1)$, two words $(n=2)$, and more than two words $(n>2)$. N-grams were identified based on the number of papers that contained them. To count this number, VOSviewer software [13] was used, as in previous studies [12, 14, 15], as well as to analyze the Scopus database without any further processing, to identify the most common keywords found from 2010 to 2020. Even though this software is primarily used for visualizing bibliometric data, it also provides the user with the ability to export data as .csv files [16]. These files contain n-grams united with the aggregated number of times that each n-gram appeared in papers. The same procedure was also followed to count the number of citations that papers containing each n-gram received.

After determining these numbers, 40 most frequently occurring n-grams based on the number of papers containing them were selected for further study. They have been determined for all eleven years together on the one hand and for certain periods usually of three years interval, on the other. Nonetheless, they were selected for all previously mentioned sets of n-grams usually considering all years together as well as selected intervals one by one.

These data were visually represented using heat maps, followed by the heat map showing countries that authors of the papers come from. Likewise, VOSviewer was used to construct a visual bibliometric network of most frequent n-grams whose color on diagram depends on different factors (the average publication year considering publication years of all the papers containing them and the average number of citations of the papers containing them, e.g.).

Lastly, a simple linear regression model was constructed, as proposed by prior research [12], to study the relationship between the number of papers published in the IJIEM where an n-gram appeared and the number of citations that the papers containing it received. Also, Pearson's correlation coefficient was estimated to determine the statistical significance of correlations. Both linear regression and correlation coefficient were analyzed with Minitab statistical software [17].

\section{Results}

As stated in the previous section, the first step in conducting this research, after cleaning the text, was to determine the most frequent n-grams that appeared in the IJIEM throughout the years. The distribution of the 40 prevailing n-grams in all eleven years, for n-grams of size 1,2 , and $n>2$, is presented in Table 1.

The frequency of occurrence was determined by comparing the number of papers containing a specific n-gram with the total number of papers that were published in the journal and inserted in the Scopus database, which is in this case 245. It is shown in the table as a percentage of papers that contain specific n-gram.

Term management is presented as the most frequent term in the IJIEM history so far since it is mentioned in almost one quarter (23\%) of the papers. It is followed by terms customization, system, product, mass, and manufacturing where each of these terms is mentioned in $13 \%$ percent of the papers, approximately. All these n-grams are associated with the aim of the IJIEM since its focus is to follow trends and innovations in the field of industrial engineering and management. Therefore, it is not surprising that combinations of these terms are also very popular, given that they appear as the most often n-grams when considering those larger than size 1.

For example, n-gram mass customization was mentioned by more than $12 \%$ of the papers, lean manufacturing in $7,5 \%$ of them while product configuration was mentioned in $3 \%$ of the papers. These percentages indicate that papers published in this journal are focused on production improvement. Similarly, many authors of IJIEM papers wrote about topics dealing with n-grams industrial engineering and management and small and medium enterprises.

On the other hand, there are not many papers that were focused on the use of information technology (IT) in production and management processes - only around 1\% up to now. This result can be seen by analyzing the n-grams information system, industry 4.0, and internet of things. 
Table 1. Distribution of the 40 prevailing n-grams in IJIEM

\begin{tabular}{|c|c|c|c|c|c|}
\hline \multicolumn{2}{|c|}{$n=1$} & \multicolumn{2}{|l|}{$\mathrm{n}=\mathbf{2}$} & \multicolumn{2}{|l|}{$n>2$} \\
\hline n-gram & $\%$ of papers & n-gram & $\%$ of papers & n-gram & $\%$ of papers \\
\hline management & 22.86 & mass customization & 12.24 & industrial engineering and management & 4.08 \\
\hline customization & 14.29 & lean manufacturing & 7.35 & small and medium enterprises (sme) & 2.86 \\
\hline system & 13.88 & industrial management & 4.90 & analytic hierarchy process & 1.22 \\
\hline product & 13.47 & small/medium enterprise & 3.27 & product configuration system & 1.22 \\
\hline mass & 13.06 & supply chain & 3.27 & solution space development & 1.22 \\
\hline manufacturing & 12.24 & product configuration & 2.86 & 3d body scanning & 0.82 \\
\hline process & 10.61 & open innovation & 2.04 & activity-based costing method & 0.82 \\
\hline controlling & 9.39 & business models & 1.63 & food supply chain & 0.82 \\
\hline performance & 8.57 & genetic algorithm & 1.63 & higher education institution & 0.82 \\
\hline business & 8.57 & human resources & 1.63 & human resource management & 0.82 \\
\hline lean & 8.16 & customer satisfaction & 1.22 & internet of things & 0.82 \\
\hline industrial & 6.94 & industry 4.0 & 1.22 & product lifecycle management & 0.82 \\
\hline service & 6.94 & literature review & 1.22 & product-service-systems & 0.82 \\
\hline innovation & 6.53 & neural network & 1.22 & supply chain management & 0.82 \\
\hline supply & 6.53 & process improvement & 1.22 & theory of constraints & 0.82 \\
\hline control & 6.53 & product development & 1.22 & 4 t tetrahedron ecodynamic model & 0.41 \\
\hline customer & 6.53 & project management & 1.22 & access control as a service (acaas) & 0.41 \\
\hline industry & 6.53 & purchase intention & 1.22 & application lifecycle management & 0.41 \\
\hline chain & 6.12 & six sigma & 1.22 & atomic force microscopy (afm) & 0.41 \\
\hline engineering & 5.31 & product lifecycle & 1.22 & authentic case methodology & 0.41 \\
\hline project & 5.31 & business process & 0.82 & bayesian belief network (bbn) & 0.41 \\
\hline design & 5.31 & case study & 0.82 & benefits of product configuration systems & 0.41 \\
\hline analysis & 4.49 & construction industry & 0.82 & bionic assembly system & 0.41 \\
\hline experience & 4.49 & continuous improvement & 0.82 & business continuity management & 0.41 \\
\hline human & 4.49 & croatian companies & 0.82 & business process management & 0.41 \\
\hline logistics & 4.49 & curriculum analysis & 0.82 & buyer-supplier relationships & 0.41 \\
\hline planning & 4.49 & customer co-creation & 0.82 & capital goods industry & 0.41 \\
\hline quality & 4.49 & customer experience & 0.82 & challenges of product configuration systems & 0.41 \\
\hline configuration & 4.08 & decision making & 0.82 & client-server communication & 0.41 \\
\hline enterprise & 3.67 & degree program & 0.82 & collaborative virtual environment & 0.41 \\
\hline model & 3.67 & early phases & 0.82 & optimization, computational simulation & 0.41 \\
\hline optimization & 3.67 & financial performance & 0.82 & companies economic performance & 0.41 \\
\hline small & 3.27 & firm performance & 0.82 & concurrent product-process-supply chain & 0.41 \\
\hline sustainability & 3.27 & food supply chain & 0.82 & configure-to-order products & 0.41 \\
\hline development & 3.27 & gender differences & 0.82 & container loading problem (clp) & 0.41 \\
\hline strategy & 3.27 & human capital & 0.82 & containers for devices & 0.41 \\
\hline risk & 3.27 & implementation guidelines & 0.82 & cost calculation accuracy & 0.41 \\
\hline software & 3.27 & information system & 0.82 & courts of law & 0.41 \\
\hline
\end{tabular}

A visual bibliometric network shown in Figure 2 was generated by VOSviewer software. It was constructed to graphically display the most common ngrams from all IJIEM papers that are covered by this research. $\mathrm{N}$-gram names are associated with circles, while the size of the circle depends on the frequency of occurrence of that n-gram in the papers. Furthermore, circle color depends on the average year of publication of the papers containing a certain ngram.
Since this research covers papers published in the period between 2010 and 2020, a legend in the bottom right corner of the figure contains a color scale where each shade is used to represent the different years in this period. Brighter colors represent that on average newer papers contain the observed ngram while darker colors mean older papers. Shades of light green and yellow color in Figure 2 indicate that topics like controlling, increasing efficiency and performance, as well as the development of business 


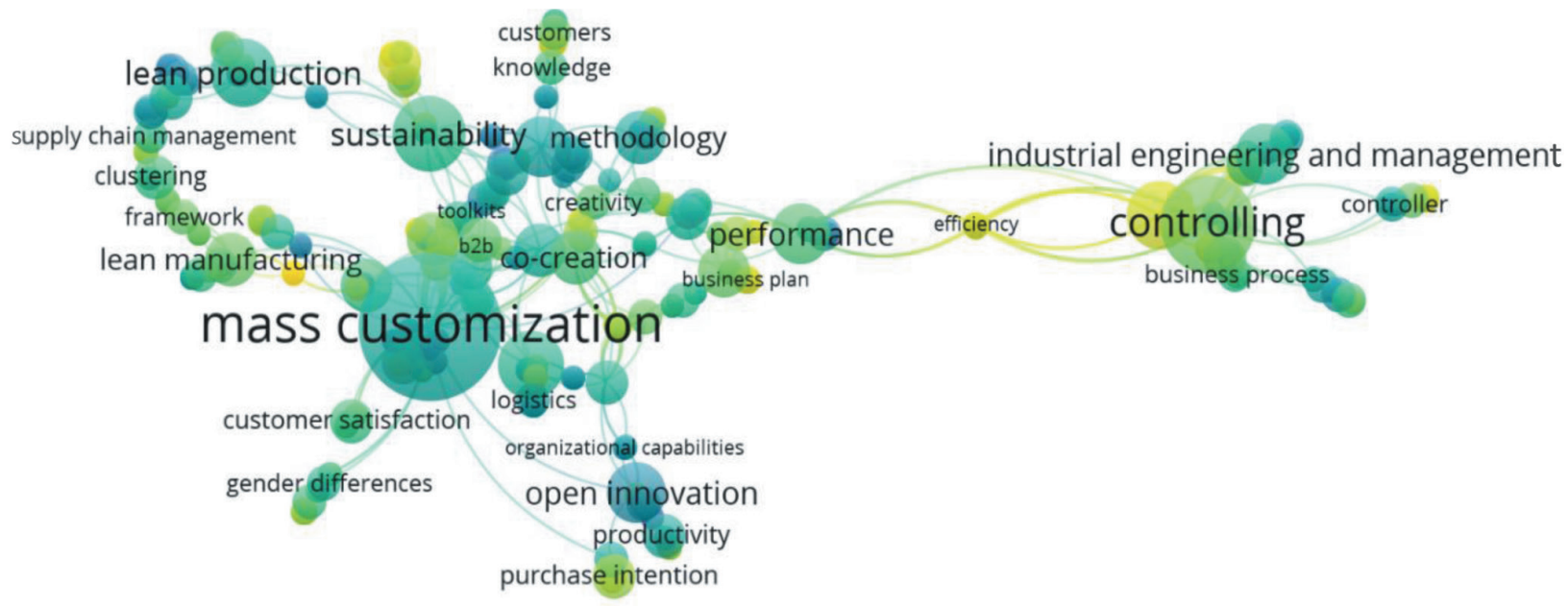

vosviewer

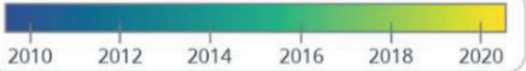

Figure 2. The most common n-grams by far, colored by the average publication year of papers containing them

plans are becoming immensely popular in the years starting from 2018. Similarly, focus on customers and their satisfaction is noticeable in the same period given that n-grams customers, purchase intention, customer satisfaction, and b2b are painted in lighter shades.

Innovation topics, in general, can be found in almost $7 \%$ of the papers, while open innovation was mentioned in $2 \%$ of them. Still, most of the papers containing this n-gram were published in the first half of the decade considering that the circle which contains it in Figure 2 is shaded in darker blue color.

\subsection{Popular topics throughout the years}

Data shown in Table 1 represent the general popularity of n-grams in IJIEM, regardless of the time in which the papers containing them were published. Because of that, this table is not thorough enough to show the popularity that different n-grams and topics had in different periods of time. Most popular ngrams based on the year in which papers containing them were published were selected with a purpose to overcome this shortcoming.

Publication years of n-grams were grouped in four intervals of time and each of them is shown as a separate column in Table 2, where each column contains 40 most frequent n-grams for the given period of time. The difference from the previous table is that columns in Table 2 combine n-grams of size 2 and larger than 2, while n-grams of size 1 were not examined per year since they individually do not give any useful information for conducting research of the most popular trends and topics in the journal. Instead of that, most of these n-grams were included in the analysis as part of n-grams of size larger than 1.

As already stated, results that are presented in Table 1 showed that mass customization is the most popular n-gram when all papers are considered together. These results are confirmed in Table 2 , since this n-gram can be found in the top five n-grams when considering each column individually. Moreover, it is mentioned in almost 30 percent of the papers that were published in the first interval of time.

It should not be neglected that globalization and internationalization led to market oversaturation. Because of that companies are faced with a need to find a way for achieving a competitive advantage while mass customization could be the right way to do that since it provides a customer with an opportunity to buy a unique, personalized product at a low price [18]. Consequently, it is not surprising that the authors of analyzed IJIEM papers have largely focused precisely on this business concept. Some of the authors even concluded that the advantages of this concept can be observed from the point of view of 6 factors: price, website information quality, design freedom, trust, visual presentation of the products and individual differences [19].

However, the fact that the percentage of the papers that contain this n-gram decreases in each subsequent period should not be neglected. This indicates that this topic is becoming less and less interesting to the authors, which leads to an assumption that the 
Table 2. 40 most frequent n-grams for individual periods

\begin{tabular}{|c|c|c|c|c|c|c|c|c|c|}
\hline n-gram & $\begin{array}{c}\text { All } \\
\text { years }\end{array}$ & n-gram & $\begin{array}{c}2010- \\
2012\end{array}$ & n-gram & $\begin{array}{c}2013- \\
2015\end{array}$ & n-gram & $\begin{array}{c}2016- \\
2018\end{array}$ & n-gram & $\begin{array}{c}2019- \\
2020\end{array}$ \\
\hline mass customization & 12.24 & mass customization & 27.08 & lean manufacturing & 11.11 & mass customization & 12.86 & business controlling & 19.57 \\
\hline lean manufacturing & 7.35 & $\begin{array}{l}\text { industrial engineering and } \\
\text { management }\end{array}$ & 10.42 & product development & 6.17 & business process & 11.43 & $\begin{array}{l}\text { mass } \\
\text { customization }\end{array}$ & 8.70 \\
\hline industrial management & 4.90 & open innovation & 8.33 & supply chain management & 6.17 & customer satisfaction & 8.57 & customer experience & 8.70 \\
\hline $\begin{array}{l}\text { industrial engineering } \\
\text { and management }\end{array}$ & 4.08 & manufacturing planning & 4.17 & $\begin{array}{l}\text { industrial engineering and } \\
\text { management }\end{array}$ & 6.17 & $\begin{array}{l}\text { product configuration } \\
\text { system }\end{array}$ & 8.57 & $\begin{array}{l}\text { performance } \\
\text { evaluation }\end{array}$ & 8.70 \\
\hline $\begin{array}{l}\text { small/medium } \\
\text { enterprise }\end{array}$ & 3.27 & lean manufacturing & 4.17 & mass customization & 4.94 & innovation process & 7.14 & purchase intention & 4.35 \\
\hline supply chain & 3.27 & process planning & 4.17 & $\begin{array}{l}\text { small and medium } \\
\text { enterprises (sme) }\end{array}$ & 3.70 & lean manufacturing & 7.14 & $\begin{array}{l}\text { consumer } \\
\text { perception }\end{array}$ & 4.35 \\
\hline product configuration & 2.86 & process improvement & 4.17 & project management & 3.70 & management styles & 5.71 & decision making & 4.35 \\
\hline $\begin{array}{l}\text { small and medium } \\
\text { enterprises (sme) }\end{array}$ & 2.86 & $\begin{array}{l}\text { application lifecycle } \\
\text { management }\end{array}$ & 2.08 & idea management & 3.70 & business models & 5.71 & $\begin{array}{l}\text { environmental } \\
\text { sustainability }\end{array}$ & 4.35 \\
\hline open innovation & 2.04 & audience fragmentation & 2.08 & process improvement & 3.70 & customer co-creation & 5.71 & $\begin{array}{l}\text { financial } \\
\text { performance }\end{array}$ & 4.35 \\
\hline business models & 1.63 & business strategy & 2.08 & $\begin{array}{l}\text { buyer-supplier } \\
\text { relationships }\end{array}$ & 3.70 & $\begin{array}{l}\text { supply chain } \\
\text { management }\end{array}$ & 5.71 & lean manufacturing & 4.35 \\
\hline genetic algorithm & 1.63 & capital goods industry & 2.08 & early phases & 2.47 & sustainable business & 4.29 & product modeling & 4.35 \\
\hline human resources & 1.63 & dynamic balance & 2.08 & operations management & 2.47 & $\begin{array}{l}\text { performance } \\
\text { measurement }\end{array}$ & 4.29 & working conditions & 4.35 \\
\hline customer satisfaction & 1.22 & emerging markets & 2.08 & period batch control & 2.47 & neural network & 4.29 & $\begin{array}{l}\text { human resource } \\
\text { management }\end{array}$ & 4.35 \\
\hline industry 4.0 & 1.22 & foreign exchange markets & 2.08 & electricity sector & 2.47 & cloud computing & 2.86 & industry 4.0 & 4.35 \\
\hline literature review & 1.22 & health home portal & 2.08 & health care & 2.47 & project management & 2.86 & $\begin{array}{l}\text { maintenance } \\
\text { management }\end{array}$ & 4.35 \\
\hline neural network & 1.22 & humanoid robot & 2.08 & information system & 2.47 & $\begin{array}{l}\text { quality management } \\
\text { systems (qms) }\end{array}$ & 2.86 & $\begin{array}{l}\text { overall equipment } \\
\text { effectiveness }\end{array}$ & 4.35 \\
\hline process improvement & 1.22 & ict for personal health care & 2.08 & inventory control & 2.47 & human capital & 2.86 & $\begin{array}{l}\text { product lifecycle } \\
\text { management }\end{array}$ & 4.35 \\
\hline product development & 1.22 & leaders' programme & 2.08 & literature review & 2.47 & human resources & 2.86 & $\begin{array}{l}\text { activity-based } \\
\text { costing method }\end{array}$ & 2.17 \\
\hline project management & 1.22 & location-aware systems & 2.08 & manufacturing strategy & 2.47 & logistics costs & 2.86 & bcm maturity & 2.17 \\
\hline purchase intention & 1.22 & market comovement & 2.08 & performance measurement & 2.47 & $\begin{array}{l}\text { companies economic } \\
\text { performance }\end{array}$ & 2.86 & $\begin{array}{l}\text { business continuity } \\
\text { management }\end{array}$ & 2.17 \\
\hline six sigma & 1.22 & market correlations & 2.08 & product lifecycle & 2.47 & product personalisation & 2.86 & business plan & 2.17 \\
\hline product lifecycle & 1.22 & market microstructure & 2.08 & risk management & 2.47 & $\begin{array}{l}\text { small and medium } \\
\text { enterprises (smes) }\end{array}$ & 2.86 & business result & 2.17 \\
\hline $\begin{array}{l}\text { analytic hierarchy } \\
\text { process }\end{array}$ & 1.22 & media management & 2.08 & road transport & 2.47 & strategic management & 2.86 & cable harness & 2.17 \\
\hline $\begin{array}{l}\text { product configuration } \\
\text { system }\end{array}$ & 1.22 & mhealth console & 2.08 & analytic hierarchy process & 2.47 & $\begin{array}{l}\text { industrial engineering } \\
\text { and management }\end{array}$ & 2.86 & cemented carbide & 2.17 \\
\hline $\begin{array}{l}\text { solution space } \\
\text { development }\end{array}$ & 1.22 & mobile health care & 2.08 & procurement process & 2.47 & online trading & 2.86 & chipping resistance & 2.17 \\
\hline business process & 0.82 & mobile services & 2.08 & quality management & 2.47 & solution space & 2.86 & $\begin{array}{l}\text { co-design } \\
\text { experience }\end{array}$ & 2.17 \\
\hline case study & 0.82 & $\begin{array}{l}\text { modular product } \\
\text { architecture }\end{array}$ & 2.08 & six sigma & 2.47 & 3d-technology & 1.43 & $\begin{array}{l}\text { collaborative virtual } \\
\text { environment }\end{array}$ & 2.17 \\
\hline construction industry & 0.82 & motion approximation & 2.08 & genetic algorithm & 2.47 & academic research & 1.43 & $\begin{array}{l}\text { construction } \\
\text { industry }\end{array}$ & 2.17 \\
\hline $\begin{array}{l}\text { continuous } \\
\text { improvement }\end{array}$ & 0.82 & nonlinear motion control & 2.08 & $\begin{array}{l}\text { customer experience } \\
\text { management }\end{array}$ & 2.47 & $\begin{array}{l}\text { access control as a } \\
\text { service (acaas) }\end{array}$ & 1.43 & $\begin{array}{l}\text { credit sales and } \\
\text { receivables }\end{array}$ & 2.17 \\
\hline croatian companies & 0.82 & open evaluation & 2.08 & supplier performance & 2.47 & additive manufacturing & 1.43 & croatian companies & 2.17 \\
\hline curriculum analysis & 0.82 & performance management & 2.08 & thermal comfort & 2.47 & automotive industry & 1.43 & cross-training & 2.17 \\
\hline customer co-creation & 0.82 & pid controller & 2.08 & sustainable business & 2.47 & brand attitude & 1.43 & degree program & 2.17 \\
\hline customer experience & 0.82 & project strategy & 2.08 & assembling process & 1.23 & cad software & 1.43 & electronic commerce & 2.17 \\
\hline decision making & 0.82 & project structure & 2.08 & bar code & 1.23 & chemical industry & 1.43 & example scenarios & 2.17 \\
\hline degree program & 0.82 & project success & 2.08 & blood bank & 1.23 & configurator features & 1.43 & fiscal responsibility & 2.17 \\
\hline early phases & 0.82 & project type & 2.08 & cargo transport & 1.23 & containers for devices & 1.43 & $\begin{array}{l}\text { greedy randomized } \\
\text { adaptive search } \\
\text { procedure (grasp) }\end{array}$ & 2.17 \\
\hline financial performance & 0.82 & $\begin{array}{l}\text { public broadcasting } \\
\text { service }\end{array}$ & 2.08 & change methodology & 1.23 & cross cultural & 1.43 & heavy machine & 2.17 \\
\hline firm performance & 0.82 & $\begin{array}{l}\text { reconfigurable } \\
\text { manufacturing system }\end{array}$ & 2.08 & clearing function & 1.23 & decision analysis & 1.43 & $\begin{array}{l}\text { higher education } \\
\text { institution }\end{array}$ & 2.17 \\
\hline food supply chain & 0.82 & $\begin{array}{l}\text { seamless mhealth service } \\
\text { delivery }\end{array}$ & 2.08 & communication patterns & 1.23 & decision making & 1.43 & hotel industry & 2.17 \\
\hline gender differences & 0.82 & service platforms & 2.08 & competence profile & 1.23 & $\begin{array}{l}\text { degree of product } \\
\text { customization }\end{array}$ & 1.43 & $\begin{array}{l}\text { industrial } \\
\text { engineering and } \\
\text { management }\end{array}$ & 2.17 \\
\hline $\begin{array}{l}\text { Total papers per } \\
\text { period }\end{array}$ & 245 & & 48 & & 81 & & 70 & & 46 \\
\hline
\end{tabular}


importance of applying the principle of mass customization in business, from the aspect of management, is potentially becoming less significant. Because of that, we can expect that some other principles (or modifications of this one) could prevail in the future.

All four functions of management (planning, organizing, leading and controlling) are equally important and represent the pillar on which the entire science of management is built [20]. Results in the table indicate that for authors of IJIEM papers planning was the most popular of these functions in the first examined interval since two n-grams (manufacturing planning and process planning) whose area of interest is planning can be found in the top five n-grams of that period. However, n-grams associated with planning can only be found in that first period. In the other three periods, there could not be found any n-gram that refers to this function of management. Similarly, n-grams associated with controlling function appear only in the last period, where almost 20 percent of the papers have written about it (considering n-gram business controlling) which make it by far the most common n-gram in that period. The increased interest of the authors of IJIEM papers in controlling in recent years could potentially mean that the general interest in this area has also increased. Also, obtained results potentially indicate that from a business aspect there is a different interest for different functions of management at different moments. However, in order to claim these assumptions with certainty, it would be necessary to conduct more detailed re- search, which would include the analysis of papers from a large number of different journals, as well as the conduction of special research that serves this purpose.

It is noticeable in Table 2 that n-gram industrial engineering and management was very popular in papers published in the first five years while, on the other hand, it appears only in a few papers when the last two periods are observed. Further, topics about people are becoming attractive for authors given that the last column in the table contains n-grams about both customers and employees such as customer experience, purchase intention, consumer perception, working conditions, and human resource management. Also, terms associated with customers are noticeable in the third column. For instance, customer satisfaction and customer co-creation can be found in a group of the most favored n-grams for that period.

The heat map shown in Figure 3 visually represents the 40 most famous n-grams in the IJIEM in general, for all periods, in combination with each period. Every intersection of the row and column is colored in a certain shade of blue color. The shade of blue depends on the presence of the n-grams from the observed row in the papers published in the period presented in the observed column. Darker color means that the number of papers containing the considered n-gram is higher, and vice versa. Legend in the right corner of the figure shows the scale of color shades to the number of papers. Heat map is consistent with the data from previous tables. The most in-

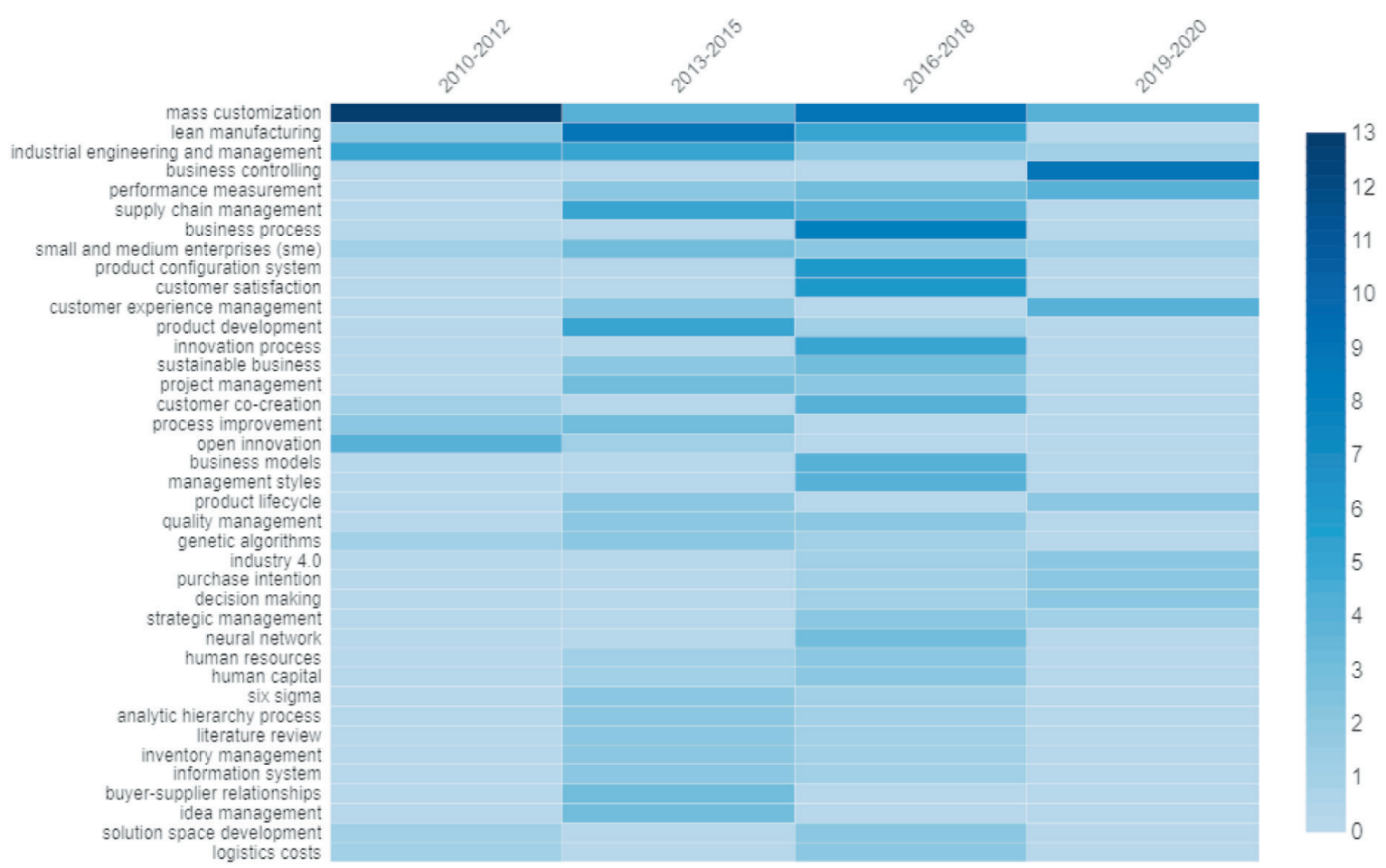

Figure 3. Heat map of 40 most frequent $n$-grams for individual periods, colored by the number of papers 
tense colors are associated with mass customization, performance measurement, and lean manufacturing.

It is interesting to see that n-gram industrial engineering and management was less attractive for authors of IJIEM papers as time went by. The reason for this may be that the authors were focusing more on specific areas of industrial engineering and management in the last few years, rather than on this topic in general. For example, management styles, product configuration system, decision making, and purchase intention are some of the n-grams that were not mentioned in any papers that were written in the first five years of IJIEM but, at the same time, are becoming popular in the years after 2015 .

On the other hand, the popularity of n-grams performance measurement and small and medium enterprises (SME) is rising in each subsequent period. Some of the IJIEM papers showed that planning can have an impact on success in SMEs only in cases when the activities defined by the business plan are actually implemented. If they are defined only to fulfill formality requirements, planning has almost no impact on success in SMEs [21]. Besides that, interdisciplinarity of SMEs should not be neglected since its three perspectives (co-creation, solution space development and information system design) are highly interwoven [22]. Also, customer experience management was mentioned in a notable number of papers in the last period. This data is aligned with the results that Kankam-Kwarteng et al. [23] presented in their study. They found out that orientation on customers in SMEs can significantly affect firm performance. This indicates that it is possible to establish a link between the attractiveness of these n-grams. Some authors consider performance evaluation a key component in the quality execution of managerial tasks which further emphasizes the importance of analyzing and improving this concept [24].

\subsection{The scientific impact of topics}

To determine the scientific contribution of papers published in the IJIEM heat map of citations that the above-mentioned papers received was created, considering the same n-grams as the heat map which is presented in Figure 3. Similarly, as in the previous figure, shades of blue color were used to express the number of citations. This heat map is shown in Figure 4.

The heat map that is presented in Figure 4 shows that papers published in a period between 2013 and 2015 are the most cited since the second column contains the highest number of dark fields. On the other hand, papers published in the last period (2019-2020) hardly received any citations. This is not surprising since this research is conducted in the first half of 2021.

$\mathrm{N}$-gram with the highest number of citations is mass customization which is expected if we take into account that almost $13 \%$ of papers ever published in IJIEM have researched this topic. Also, a very popular topic from the aspect of the number of citations is the relationship with customers. This can be seen if n-grams customer co-creation and buyer-seller relationship are taken into account. Interestingly, papers that wrote about business models were highly cited even though there were only 4 of them - they received 63 citations together. Nonetheless, papers containing n-grams product development, sustainable business, performance measurement, and process improvement received a significant number of citations in certain periods. This indicates that over time authors of the IJIEM papers examined different factors that influence a company's ability to make the value.

Similarly, although only 3 papers wrote about Industry 4.0, the number of citations these papers have received is large (49 together). One of them is a review paper and it is the most cited article in the IJIEM journal. It is expected that the trend of continuous growth in the number of papers published in the IJIEM that research this topic will continue to rise and that those papers will receive even more citations. This expectation comes from the fact that the concept of Industry 4.0 is becoming more and more popular in recent years. Also, the number of companies that implement Industry 4.0 is growing since it has the potential to drastically improve complex industrial ecosystems by introducing new technologies [25].

Similar to Figure 2, VOSviewer was used to create a network for the average number of citations for papers that contain a certain n-gram received. The lighter color of the circle means that on average the papers that contain observed n-gram are more often cited. This network is represented in Figure 5.

To determine if the popularity of n-grams in the IJIEM is connected with its received number of citations a linear regression model was created. The relationship between the number of papers that contain a certain n-gram and the number of citations that those papers received are studied in this model. This analysis was done with Minitab software. The linear regression plot is shown in Figure 6, while the analysis is presented in Figure 7. The obtained p-value is 0.000 while the significance level was 0.05 which indicates 


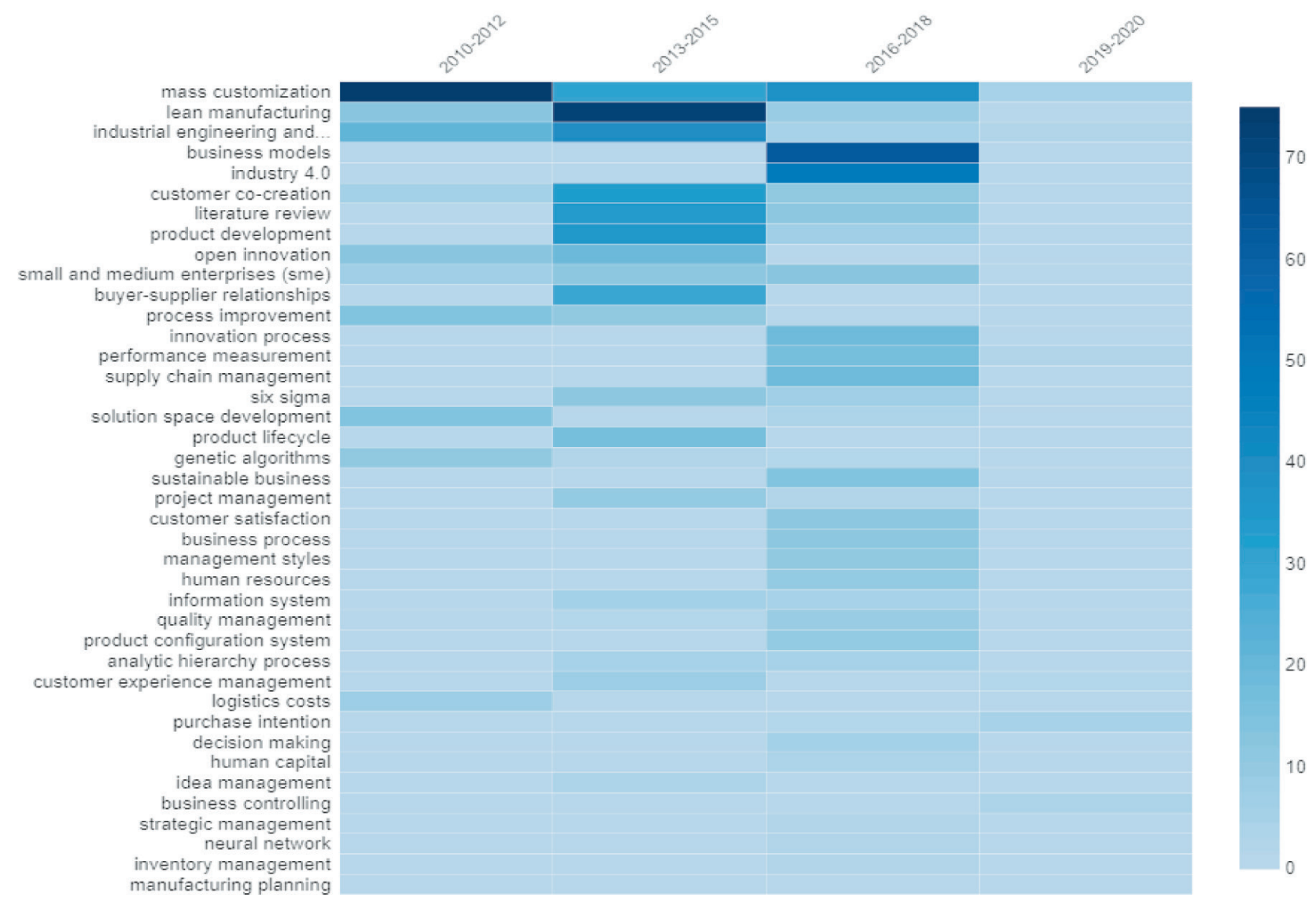

Figure 4. Heat map of 40 most frequent $n$-grams for individual periods, colored by the number of citations

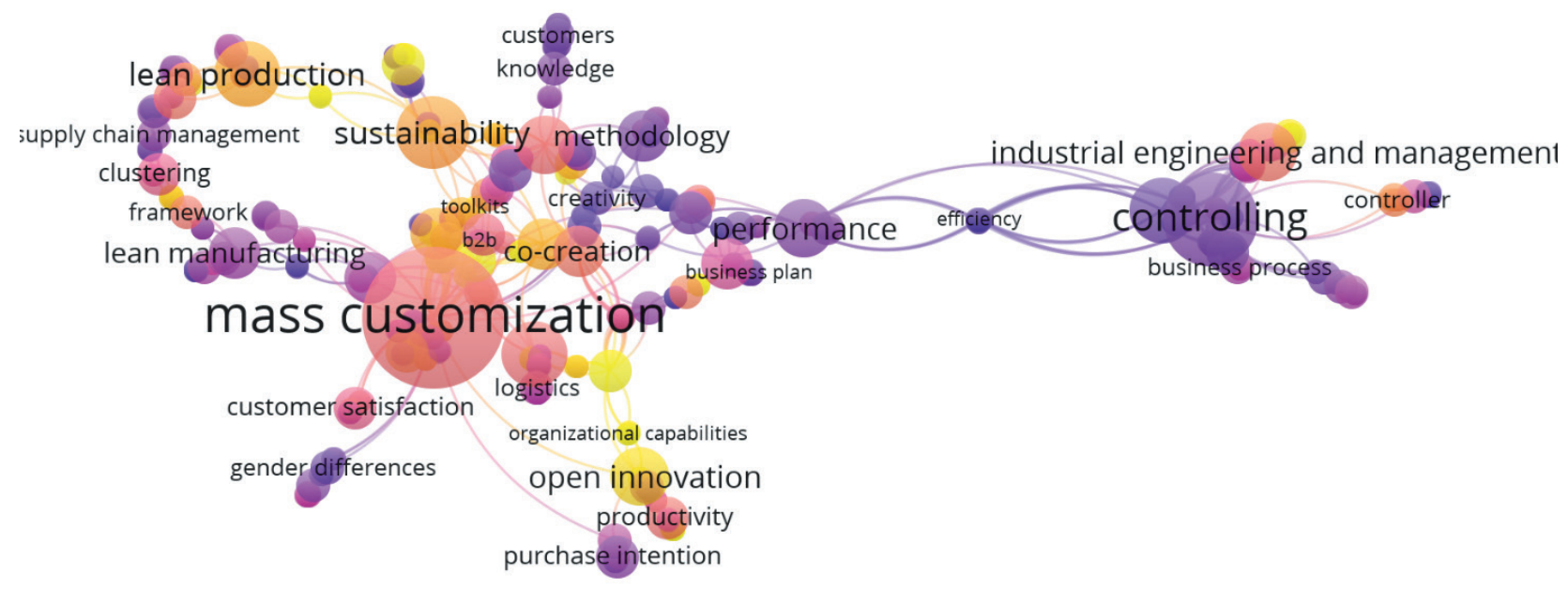

\& VOSviewer

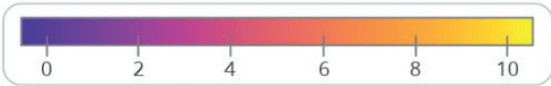

Figure 5. The most common n-grams by far, colored by the average number of citations of papers containing them 
cites $=4.741$ papers -3.668

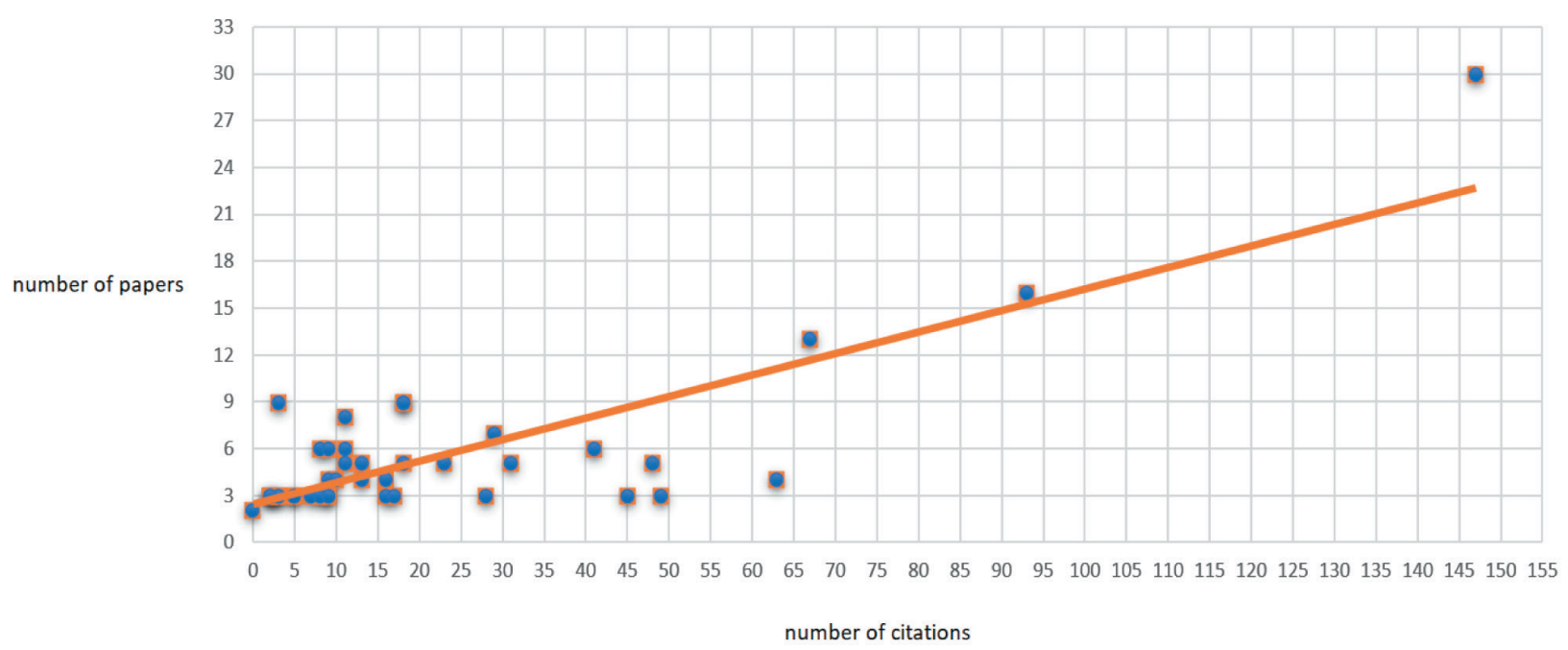

Figure 6. Linear regression model for n-grams

\section{Regression Analysis: number of citations versus number of papers}

$\begin{array}{lrrrrr}\text { Analysis of Variance } & & & \\ & & & & \\ \text { Source } & \text { DF } & \text { Adj SS } & \text { Adj MS } & \text { F-Value } & \text { P-Value } \\ \text { Regression } & 1 & 21069 & 21068.6 & 71.63 & 0.000 \\ \quad \text { number of papers } & 1 & 21069 & 21068.6 & 71.63 & 0.000 \\ \text { Error } & 38 & 11177 & 294.1 & & \\ \quad \text { Lack-of-Fit } & 9 & 3854 & 428.2 & 1.70 & 0.135 \\ \quad \text { Pure Error } & 29 & 7323 & 252.5 & & \\ \text { Total } & 39 & 32246 & & & \end{array}$

Model Summary

$\begin{array}{rrrr}\mathrm{S} & \mathrm{R}-\mathrm{sq} & \mathrm{R}-\mathrm{sq}(\operatorname{adj}) & \mathrm{R}-\mathrm{sq}(\mathrm{pred}) \\ 17.1506 & 65.34 \% & 64.42 \% & 61.01 \%\end{array}$

Coefficients

$\begin{array}{lrrrrr}\text { Term } & \text { Coef } & \text { SE Coef } & \text { T-Value } & \text { P-Value } & \text { VIF } \\ \text { Constant } & -3.67 & 4.16 & -0.88 & 0.383 & \\ \text { number of papers } & 4.741 & 0.560 & 8.46 & 0.000 & 1.00\end{array}$

Figure 7. Regression analysis for n-grams

\section{Correlation: number of papers, number of citations \\ Pearson correlation of number of papers and number of citations $=0.808$ $\mathrm{P}$-Value $=0.000$}

Figure 8. Correlation for n-grams

that the number of papers significantly influences the number of received citations.

Also, Pearson's correlation coefficient was calculated in Minitab to determine whether a statistical correlation between n-grams is significant. The ob- tained coefficient is 0.808 which means that a strong positive correlation exists between the number of papers that contain a certain n-gram and the number of citations that these papers received.

Similarly, as in Figure 7, the p-value is 0.000 which 
is smaller than the significance level (0.05). This value confirms that the number of papers that contain a certain n-gram is in correlation with the number of times these papers have been cited.

Table 3 was created with the purpose to present the most cited papers ever published in the IJIEM. Table 3 consists of 10 rows and each row contains data about one paper. Papers in the table are ordered by a number of received citations, in descending order.

Even though mass customization is the most frequently occurring n-gram, Table 3 shows that papers that contain it are not the most scientifically influential in the IJIEM. Moreover, none of the first 10 papers mentioned this n-gram. The most influential paper in the IJIEM by far is the one whose focus was on Industry 4.0 and its concepts. As stated earlier, Industry 4.0 has not often been the main subject of interest of the authors of papers from this journal but this result indicates that more attention should be paid to it in future papers. Also, very popular IJIEM papers were mostly focused on defining business strategies, find- ing a way to improve performance, and improving relationships with customers.

The last heat map, shown in Figure 9, visually represents the countries of origin of authors of IJIEM papers. Countries were selected for all authors of every IJIEM paper ever published and shown in the heat map as rows. Similar to previous heat maps one column represents one period of time. Intersect of row and column defines the number of papers in the observed period whose authors come from the observed country.

Figure 9 depicts that the most dominant country from the perspective of authors of the IJIEM papers is Serbia. This result is not surprising given that the journal itself is published in Serbia. Apart from Serbia, the heat map shows that scientists from Germany, Portugal, Italy, and Brazil have been finding the IJIEM as an adequate journal for publishing their research in all periods. On the other hand, authors from the United States, Finland, and Sweden have made a scientific contribution through this journal in the first five years but did not publish many papers

Table 3. First 10 most cited papers ever published in the IJIEM

\begin{tabular}{|c|c|c|c|c|}
\hline First author & Title & Year & Citations & N-grams \\
\hline Crnjac M. & $\begin{array}{l}\text { From concept to the introduction of } \\
\text { industry } 4.0\end{array}$ & 2017 & 49 & $\begin{array}{l}\text { Business concept; Industry 4.0; Business } \\
\text { model; }\end{array}$ \\
\hline Godina R. & $\begin{array}{l}\text { Quality improvement with statistical process } \\
\text { control in the automotive industry }\end{array}$ & 2016 & 22 & $\begin{array}{l}\text { Decision analysis; Quality control; Quality } \\
\text { improvement; Statistical process control; }\end{array}$ \\
\hline Zunk B.M. & $\begin{array}{l}\text { The role of E-procurement in the Austrian } \\
\text { construction industry: Adoption rate, } \\
\text { benefits and barriers }\end{array}$ & 2014 & 22 & $\begin{array}{l}\text { Buyer-supplier relationships; Industrial } \\
\text { markets; Procurement process; }\end{array}$ \\
\hline Mesquita D. & $\begin{array}{l}\text { Industrial Engineering and Management } \\
\text { curriculum profile: Developing a framework } \\
\text { of competences }\end{array}$ & 2015 & 20 & $\begin{array}{l}\text { Competences; Curriculum analysis; } \\
\text { Industrial Engineering and Management }\end{array}$ \\
\hline Ceryno P.S. & $\begin{array}{l}\text { Supply chain risk management: A content } \\
\text { analysis approach }\end{array}$ & 2013 & 20 & $\begin{array}{l}\text { Conceptual framework; Literature } \\
\text { review; Risk management; Supply chain } \\
\text { management; }\end{array}$ \\
\hline Maia L.C. & $\begin{array}{l}\text { Sustainable work environment with lean } \\
\text { production in textile and clothing industry }\end{array}$ & 2013 & 20 & Lean Manufacturing Sustainability; \\
\hline Brunswicker S. & $\begin{array}{l}\text { Managing open innovation in SMEs: A good } \\
\text { practice example of a German software firm }\end{array}$ & 2013 & 19 & $\begin{array}{l}\text { Open innovation; Organizational change; } \\
\text { Small and Medium Enterprises (SME); }\end{array}$ \\
\hline Lima R.M. & $\begin{array}{l}\text { An analysis of knowledge areas in industrial } \\
\text { engineering and management curriculum }\end{array}$ & 2012 & 18 & $\begin{array}{l}\text { Curriculum analysis; Industrial } \\
\text { Engineering and Management; Knowledge } \\
\text { areas }\end{array}$ \\
\hline Shafiee S. & $\begin{array}{l}\text { Scoping a product configuration project for } \\
\text { engineer-to-order companies }\end{array}$ & 2014 & 17 & Product configuration; \\
\hline Lalic B. & $\begin{array}{l}\text { Open innovation in developing regions: An } \\
\text { empirical analysis across manufacturing } \\
\text { companies }\end{array}$ & 2017 & 16 & $\begin{array}{l}\text { Developing countries; European } \\
\text { manufacturing survey; Open innovation; }\end{array}$ \\
\hline
\end{tabular}




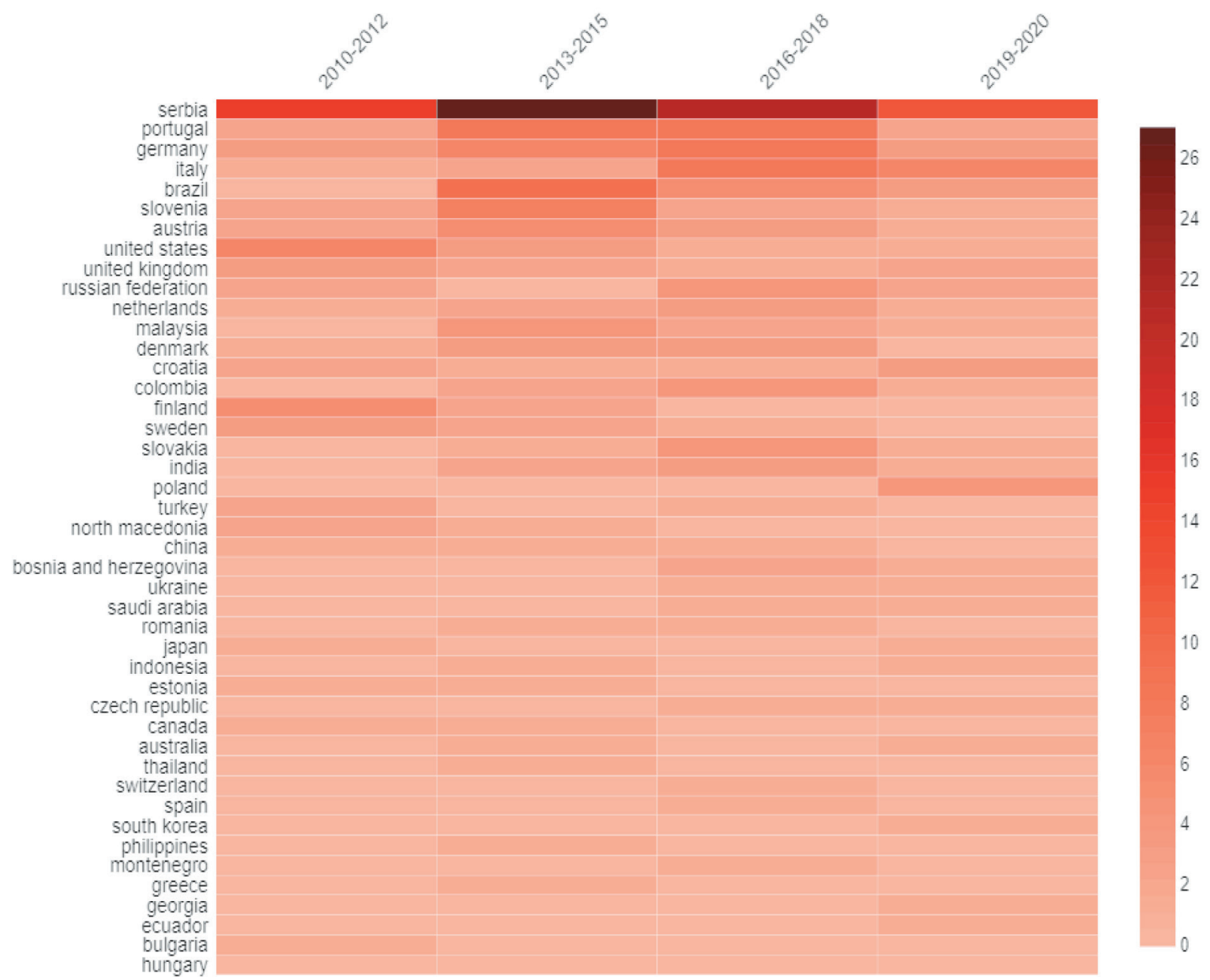

Figure 9. Heat map of countries of origin of authors of IJIEM papers for individual periods, colored by the number of papers

in the second half of the decade. Unlike them, in the years after 2015 authors from Italy, Russian Federation, Poland, and Croatia have shown interest in this journal.

\section{Discussion and future IJIEM opportunities}

The results and the findings from the conducted research are discussed in this section. The overall impression acquired by analyzing results presented in previous tables and figures is that the IJIEM is an emerging journal with a high potential for growth. The IJIEM plays an active role in the fields of industrial engineering, manufacturing engineering, and production management. Authors of the papers have shifted focus from generalized topics to more specific ones. For example, n-grams industrial engineering and management and small and medium enter- prises were highly positioned in the tables in the early years. This means that researchers were focusing on improving the performance of business management and production in general, instead of analyzing specific techniques and methods that can improve certain business segments.

However, there has been a noticeable change in this in recent years given that previously mentioned n-grams have descended to lower positions in tables while, at the same time, n-grams dealing with specific aspects of the business (such as purchase intention, decision making, and customer experience management) have moved to the higher positions.

Nonetheless, there is a noticeable increase in attention paid to topics concerning people. Specifically, customers and relationships with them are becoming very popular since 5 of the 40 most popular n-grams of all time were associated with this topic. Similarly, papers that contain n-grams human resources and human capital deal with the topic of employee manage- 
ment. Considering that some authors [26] claim that investing in the labor force is a sure way for achieving better productivity, performance, and results in general this topic should not be neglected. They argue that the reason for this is that employees have direct contact with change and are primarily responsible for its successful development. With this in mind Mijatovic et al. [27] conducted research to examine whether there is a link between human resource management and sustainable development of manufacturing firms. The results of their research show that there is a strong positive relationship between human resource management and the success of the implementation of digital technologies in manufacturing companies.

Also, some research [28] show that better financial performance could be expected from societies that have advanced processes of human capital. In addition, it would be good to pay additional attention to B2B strategies in the future. This type of customer relationship covers all segments of the supply chain: from manufacturers to suppliers to distributors, and literature reviews show that there is currently a gap in the literature [29].

Since the most influential IJIEM paper [30] by far deals with the Fourth Industrial Revolution while, at the same time, presented tables show that IT topic, in general, was not very popular in the previous years. A great opportunity for further research could be to explore the possibilities of using artificial intelligence, advanced operational and informational technologies in the execution of managerial and industrial processes [1]. The benefits of exploring this could be huge, given that Kiel et al. [30] claim that it positively affects different aspects of life at the same time - economical, ecological, and social. They state that from the economical aspect main benefits are shorter times needed to finish a job, enhanced productivity and flexibility, increased efficiency, and decreased costs. The ecological aspect is reflected in the reduction of waste and logistics processes, increasing energy efficiency, and smaller greenhouse emissions. From the social aspect, some of the expected benefits are reduction of job complexity, more creative jobs, organizational transformation, and higher wages. Besides that, Beric et al. [31] emphasize that achieving high values of the degree of effectiveness of industrial production processes is closely related to usage of Management information systems in production since it provides fast information flow and effective decision making. They argue that integrated production has a potential to be the dominant form of production in the majority of smart production systems in the future.
However, it should be noted that research [32] shows that the use of IT in companies faces different government measures and high financial requirements, which significantly affects the degree and speed of implementation of these systems within companies.

\section{Limitations of the study}

The first limitation of this study is that a time period of only eleven years was taken into account. Although that period includes papers that were published in this journal in the period from 2010 until the moment of conducting this research, it is still a fairly short period of time in terms of determining fluctuations in popular trends and topics. Therefore, a significant number of the conclusions that have been made in this research about future trends of the IJIEM are based on assumptions and expectations.

Besides that, a big part of data preparation for analysis was done manually. This method of data cleaning and its preparation for analysis was satisfactory for the purposes of this research, given that the total number of papers considered was 245. However, if the scope of papers increased, this way of data preparation could lead to various challenges. For this reason, one of the future suggestions for improvement could be to find tools and methodologies that provide automated and accelerated execution of this research step (see: [12]).

Also, a potential limitation of this paper could be that the analysis relies solely on data available in the Scopus database while at the same time there is a chance that data for some of the existing IJIEM papers are not inserted into this database. Bearing in mind that the absence of such data can significantly affect the conclusions drawn and the results obtained, in future research researchers should pay significant attention to this limitation.

Lastly, the first three periods that were selected in the analysis contained time intervals of three years while the last period contained only two years. The previously mentioned inconsistency occurred due to at the moment of conducting this research authors did not have information about IJIEM papers that were published in the current running year (2021). Thus, the last period contained data for 2019 and 2020 only. This shortcoming could potentially be the basis for conducting new research based on this one while containing equal periods. Also, the authors used only data about IJIEM pa- 
pers that were taken from the Scopus database. A chance for improvement would be to expand this information by analyzing the papers themselves. In this way, some additional data about the papers could potentially be obtained, which could be important for identifying new trends in the journal.

\section{Conclusions}

This research analyzed different trends and topics that were interesting for the authors of IJIEM papers throughout the years with an aim to provide insight into the contribution to the process of determining influence, progress and positive effect that industrial engineering and engineering management had on society through analysis of IJIEM papers.

Previously shown results could be a significant basis for authors to determine further directions of research as it shows how authors' interests in the field of industrial engineering, engineering management, and production management have changed over the years. Likewise, presented heat maps as a visual representation of popular n-grams could help researchers to determine which topics should be set as a priority in the near future, as well as the research of which scientific areas have the potential to identify new, significant, scientific achievements.

Authors of future IJIEM papers should pay attention to emphasized limitations of this study and try to find a way to overcome it given that it could lead to significant improvements and progress in the fields of industrial engineering, engineering management, and production management. Solutions to overcoming these limitations that were proposed in this paper could help them in that process. Also, suggested opportunities should not be ignored given that they were derived from the analyzed bibliometric data. Therefore they could lead authors of IJIEM papers to a chance to make a significant scientific contribution through future research and potentially make an even greater impact of industrial engineering and management on communities through them. Future analyses should be based on some novel methodological approaches such as text mining [33].

\section{Funding}

This research did not receive any specific grant from funding agencies in the public, commercial, or not-for-profit sectors.

\section{References}

[1] D. Romero, G. Von Cieminski, T. Wuest, P. Gaiardelli, I. Moon, G. Pezzotta, S. Wiesner, M. Macchi, J. Baalsrud Hauge, I. Roda, D. Powell, T. Netland, B.S. Kulvatunyou, N. Szirbik, C. Roser, E. Alfnes, and M. Rudberg, "Advances in Production Management Systems: Issues, Trends, and Vision Towards 2030," IFIP Advances in Information and Communication Technology, vol. 600, pp. 194-221, 2021. doi: 10.1007/978-3-030-81701-5 8

[2] U. Marjanovic, B. Lalic, N. Medic, J. Prester, and I. Palcic, "Servitization in manufacturing: role of antecedents and firm characteristics," International Journal of Industrial Engineering and Management, vol. 11, no. 3, pp. 146-156, 2020. doi: 10.24867/IJIEM-2020-2-259

[3] W. Hu, Y. W. Hu, W. H. Yao, W. Q. Lu, H. H. Li, and Z. W. Lv, "A blockchain-based smart contract trading mechanism for energy power supply and demand network," Advances in Production Engineering \& Management, vol. 14, no. 3, pp. 284-296, 2019. doi: 10.14743/apem2019.3.328

[4] S. R. Moro, P. A. Cauchick-Miguel, and G. H. S. Mendes, "Product-service systems benefits and barriers: an overview of literature review papers," International Journal of Industrial Engineering and Management, vol. 11, no. 1, pp. 61-70, 2020. doi: 10.24867/IJIEM-2020-1-253

[5] K. Buntak, M. Kovačić, and M. Mutavdžija, "Application of Artificial Intelligence in The Business," Int. J. Qual. Res., vol. 15, no. 2, pp. 403-416, 2021, doi: 10.24874/ IJQR15.02-03

[6] U. Marjanovic, "About IJIEM Journal," University of Novi Sad, Faculty of Technical Sciences, [Online]. Available: http://ijiemjournal.uns.ac.rs/about.html. [Accessed 10 March 2021].

[7] Elsevier, "Scopus," 2018. [Online]. Available: www.scopus. com.

[8] G. Shang, B. Saladin, T. Fry, and J. Donohue, "Twenty-six years of operations management research (1985-2010)," International Journal of Production Research, vol. 53, no. 20, pp. 6161-6197, 2015. doi: 10.1080/00207543.2015.1037935

[9] A. M. T. Thomé, L. F. Scavarda, and A. J. Scavarda, "Conducting systematic literature review in operations management," Production Planning \& Control, vol. 27, no. 5, pp. 408-420, April 2016. doi: 10.1080/09537287.2015.1129464

[10] Clarivate, " Web of Science," [Online]. Available: www. clarivate.com

[11] B. V. Elsevier, "Scopus," 2021. [Online]. Available: www. scopus.com.

[12] R. Romero-Silva and E. Marsillac, "Trends and topics in IJPR from 1961 to 2017: a statistical history," International Journal of Production Research, vol. 57, no. 15-16, pp. 4692-4718, 2019. doi: 10.1080/00207543.2018.1551638

[13] N. J. van Eck and L. Waltman, "Visualising Bibliometric Networks," Measuring Scholarly Impact: Methods and practice, pp. 285-320, 2014. doi:10.1007/s11192-009-0146-

[14] C. Cancino, J. M. Merigo, F. Coronado, Y. Dessouky and M. Dessouky, "'Forty Years of Computers \& Industrial Engineering: A Bibliometric Analysis," Computers \& Industrial Engineering, vol. 113, pp. 614-629, 2017. doi:10.1016/j.cie.2017.08.033

[15] L. Sigifredo, J. M. Merigo, M. Jaime, R. Slowinski, B. Immanuel, B. Emanuele, D. G. Robert, O. José Fernando, and T. Ruud, "Forty Years of the European Journal of Operational Research: A Bibliometric Overview," European Journal of Operational Research, vol. 262, no. 3, pp. 803-816, 2017. doi: 10.1016/j.ejor.2017.04.027 
[16] VOSviewer, "Welcome to VOSviewer," 14 May 2021. [Online]. Available: https://www.vosviewer.com/.

[17] Minitab, "Minitab POWERFUL STATISTICAL SOFTWARE EVERYONE CAN USE," Minitab, LLC, [Online]. Available: https://www.minitab.com/en-us/ products/minitab/. [Accessed 14 May 2021].

[18] J. Tiihonen and A. Felfernig, "An introduction to personalization and mass customization," Journal of Intelligent Information Systems, vol. 49, no. 2, pp. 1-7, 2017. doi: 10.1007/s10844-017-0465-4

[19] H. Zhao, L. McLoughlin, V. Adzhiev and A. Pasko, "“Why do we not buy mass customised products?" - An investigation of consumer purchase intention of mass customised products," International Journal of Industrial Engineering and Management, vol. 10, no. 2, pp. 181-190, 2019. doi: 10.24867/IJIEM-2019-2-238

[20] N. Jankelova and D. Puhovichova, "Changes in the application of methods and techniques in the implementation of managerial functions in the context of the impact the Fourth industrial revolution," INTERNATIONAL SCIENTIFIC JOURNAL "INDUSTRY 4.0", vol. 4, no. 6 , pp. 306-308, 2019.

[21] A. Ivanisevic, A. Losonc, S. Moraca, P. Vrgovic and I. Katic, "Exploring the Business Planning Practices in Smes in a Developing Country," International Journal of Industrial Engineering and Management, vol. 10, no. 1, pp. 105-114, 2019. doi: 10.24867/IJIEM-2019-1-105

[22] L. Grafmuller, S. Hankammer, S. Honigsberg and H. Wache, "Developing complex, mass-customized products in SME networks: Perspectives from co-creation, solution space development, and information system design," International Journal of Industrial Engineering and Management, vol. 9, no. 4, pp. 215-227, 2018. doi: 10.24867/IJIEM-2018-4-215

[23] C. Kankam-Kwarteng, J. Donkor and S. Acheampong, "Measuring Performance of SMEs Service Firms," Journal of Management Research, vol. 19, no. 2, pp. 103-119, 2019.

[24] P. Petera, J. Wagner and L. Soljakova, "Strategic management accounting and strategic management: The mediating effect of performance evaluation and rewarding," International Journal of Industrial Engineering and Management, vol. 11, no. 2, pp. 116-132, 2020. doi: 10.24867/IJIEM-2020-2-258

[25] L. D. Xu, E. L. Xu and L. Li, "Industry 4.0: state of the art and future trends," International Journal of Production Research, vol. 56, no. 8, pp. 2941-2962, 2018. doi: 10.1080/00207543.2018.1444806

[26] P. Blaga, "The Importance of Human Resources in the Continuous Improvement of the Production Quality," in 13th International Conference Interdisciplinarity in Engineering (INTER-ENG 2019), Targu Mures, Romania, 2020.

[27] M. Dukic Mijatovic, O. Uzelac and A. Stoiljkovic, "Effects of human resources management on the manufacturing firm performance: Sustainable development approach," International Journal of Industrial Engineering and Management, vol. 11, no. 3, pp. 205-212, 2020. doi: 10.24867/IJIEM-2020-3-265

[28] I. Korobanicova and N. Kovacova, "Human Capital Investment: Practices and Measurement In Slovak Enterprises," International Journal of Industrial Engineering and Management, vol. 9, no. 3, pp. 139-146, 2018. doi: 10.24867/IJIEM-2018-3-139

[29] J. Alonso-Garcia, F. Pablo-Marti and E. Nunez-Barriopedro, "Omnichannel Management in a B2B context: Concept, research agenda and bibliometric review," International Journal of Industrial Engineering and Management, vol. 12, no. 1, pp. 37-48, 2021. doi: 10.24867/IJIEM-2021-1-275
[30] M. Crnjac, I. Veza, and N. Banduka, "From concept to the introduction of industry 4.0," International Journal of Industrial Engineering and Management, vol. 8, no. 1, pp. 21-30, 2017.

[31] D. Kiel, J. Muller, C. Arnold and K.-I. Voigt, "Sustainable Industrial Value Creation: Benefits and Challenges of Industry 4.0," International Journal of Innovation Management, vol. 21, no. 8, 2017. doi: 10.1142/ S1363919617990018

[32] D. Beric, D. Stefanovic, B. Lalic and I. Cosic, "The Implementation of ERP and MES Systems as a Support to Industrial Management Systems," International Journal of Industrial Engineering and Management, vol. 9, no. 2, pp. 77-86, 2018.

[33] I. Bestvina Bukvic and I. Djurdjevic Babic, "The Impact of Government Measures on Business Development in the ICT sector," International Journal of Industial Engineering and Management, vol. 12, no. 1, pp. 63-72, 2021. doi: 10.24867/IJIEM-2021-1-277 